\title{
Fate of elements: Unwanted mineral formation in biogas engines
}

\author{
A. KHAIDI $^{1 *}$, E. HARMAN-TÓTH ${ }^{1}$, I. GÖNCZI ${ }^{2}$, \\ T. MireISZ ${ }^{3}$, T. KÖVÁRI ${ }^{3}$ AND T.G. WEISZBURG ${ }^{1}$ \\ ${ }^{1}$ Dept. of Mineralogy, Eötvös Loránd Univ., 1117, Budapest, \\ Hungary (* correspondence: ameershabreen@gmail.com) \\ ${ }^{2}$ NRG Group, 6000, Kecskemét, Hungary \\ ${ }^{3}$ Budapest Waterworks, 1138, Budapest, Hungary
}

Biogas, produced through anaerobic digestion of waste materials (municipal solid waste in landfills, sewage, food waste, agricultural waste) is a green energy source over the conventional fossil fuels. Cogeneration technology, fuelled with biogas, produces both heat and electricity.

The main technological challenge in the biogas-to-energy industry is the solid deposition on the gas engines reaching thickness over the $\mathrm{mm}$ range, deteriorating engine working conditions and increasing maintenance needs. In the burning process essential $\left(\mathrm{CH}_{4}, \mathrm{CO}_{2}\right)$ and detrimental $\left(\mathrm{H}_{2} \mathrm{~S}\right.$, various siloxanes) biogas components, air, engine parts and lubricating oil may interact. High-temperature and constantly changing pressure conditions of the internal-combustion engines, with special flow dynamics lead to the formation of both glassy (short-range-order only; SRO) and crystalline phases, and due to the interaction of C- and Si-based systems, represent a special paragenetic challenge for mineralogists. Characterisation of the deposits and understanding their formation processes can help to improve the technology.

We sampled solid engine deposits formed from biogas generated during two different processes: urban waste landfill (UWL), and wastewater treatment (WWT). In the two UWL facilities the combustion chambers of 12- and 16-cylinder Caterpillar $^{\circledR}$ engines, while at the WWT plant in Budapest both the compression input chambers and the mixed-gas chambers of a 20 -cylinder Jenbacher ${ }^{\circledR}$ engine were analysed.

In the UWL combustion chambers deposition of crystalline phases (anhydrite $-\mathrm{Ca}\left[\mathrm{SO}_{4}\right]$; cristobalite \& quartz - $\mathrm{SiO}_{2}$ polymorphs) beside the dominant Ca-silicate glass could be observed. The compression input chambers at the WWT unit suffered deposition of silicon both in oxidic $\left(\mathrm{SiO}_{2}\right.$ polymorphs: quartz, tridymite, cristobalite; SRO?) and carbidic (SiC: moissanite) forms. The mixed-gas chamber, representing totally different technological conditions, was characterized by the deposition of various crystalline copper compounds, including covellite $(\mathrm{CuS})$ and antlerite $\left(\mathrm{Cu}_{3}\left[\mathrm{SO}_{4}\right](\mathrm{OH})_{4}\right)$. The presence of these phases (oxide/carbide; sulphide/sulphate) indicate spatial (and temporal) variability in redox conditions, too.

Support is thanked for ELTE 1783-3/2018/FEKUTSRAT Institutional Excellence Program and Koch S. Foundation. 